\title{
Neonatal Death with Relation to Institutional Delivery in North- Eastern States of India
}

\author{
Tushar Dakua $^{*}$, Manoj Alagarajan ${ }^{2}$ \\ ${ }^{I}$ Master of Population Studies, International Institute for Population Sciences, Mumbai, Maharastra \\ ${ }^{2}$ Professor at IIPS Mumbai
}

*Corresponding Author: Tushar Dakua, Master of Population Studies, International Institute for Population Sciences, Mumbai, Maharastra

\begin{abstract}
Background: Millennium development goal sets a target to achieve the goal of reducing child mortality for all countries. However, a decline in neonatal mortality for developing countries was prolonged. In India reduction in neonatal mortality was led by institutional delivery along with several other factors. As the government of India has implemented various policies to promote institutional delivery.
\end{abstract}

Methods: The present study analyzes data from the National Family Health Survey, 2015-16 (NFHS-IV). A total of 179752 births (last birth) and 3774 neonatal death were recoded in last 1 Year in North-eastern states of India. Logistic regression is attempted to understand the correlates of Institutional delivery. Logistic regression was used to assess the factors responsible for neonatal death in North-Eastern states of India.

Results: In Sikkim, almost all deliveries took place at institutions whereas Nagaland is having the highest cases of non-institutional delivery. Highest neonatal death prevails in the state of Assam, whereas Mizoram and Arunachal Pradesh are having few neonatal death. Institutional delivery has a good positive relation with neonatal death whereas non-institutional delivery is negatively related to neonatal death.

Conclusion: This study indicates the role of different socio-economic factors on institutional delivery as a part of to promote neonatal survival. Found that the influence of institutional delivery is not much on neonatal death. This may be because there are several variables which affect the pattern of neonatal death of an area. But from the study, it is found that delivery at Non-Institution is still higher in some of the states like Nagaland. While Assam is having highest neonatal death because of Tea garden workers.

\section{BACKGROUND}

The term neonate refers to a live-born infant from birth to before reaching 28 completed days of age whereas neonatal mortality rate (NMR) refers to the number of live born babies who die in the first 28 days after live birth per 1000 live birth.

The Sustainable Development Goal for neonatal deaths requires all countries to bring down the figure to 12 deaths or less per 1,000 births by 2030 . Neonatal mortality is one of the main problems in infant life. Mortality of any region is greatly influenced by death within one month of live birth. Neonatal mortality can be considered as the most sensitive indicator for observing the health status of our nation. Integral on demographic research on neonatal mortality are studies of an event like the death of a live-born infant before 28 completed days of age. Aim of this paper was to provide information that can guide the development of preventive strategies for identified problems, to reduce the incidence of neonatal deaths.

Almost all deaths due to asphyxia occur in the first week of life, with $70 \%$ of them occurring within the first 24 hours (day 0 ). About three fourth of deaths due to prematurity $(74.8 \%$ ) occur in the first week of life, and less than $50 \%$ of neonatal deaths occur in the first week of life. About $30 \%$ of sepsis-related deaths occur in the second week, whereas around one fifth occur in the fourth week. Contributing to nearly half of these deaths.

The NMR is not uniform across the country. Although Kerala and TN have low NMR (less than 20 per 1000 live birth) Odisha, MP, UP have very high NMR (35 per 1000 live birth). Four states - Uttar 
Pradesh, Madhya Pradesh, Bihar, and Rajasthan-alone contribute to 55\% of total neonatal deaths in India and to $15 \%$ of global neonatal deaths that occur every year.

The unacceptable number of deaths being witnessed in India over the past months is, just an example of what the study had warned of and much more. "There is an interplay of different demographic, educational, socioeconomic, biological and care-seeking factors, which are responsible for the disparities and the high burden of neonatal mortality. The country has to increase the coverage of key interventions and also improve the quality of care in health facilities on an urgent basis,' the study had emphatically said.

India has witnessed a significant improvement in neonatal health after the introduction of the National Rural Health Mission. Apart from the Janani Suraksha Yojana, the country has launched several new initiatives to improve neonatal care facilities. This newfound focus on newborn health, the annual rate of reduction in the NMR and Early NMR is still lags behind Infant Mortality Rate.

Institutional deliveries indicate access to neonatal as well as postnatal health care. Except for Mizoram, Sikkim, and Tripura, share of institutional deliveries in other states was less than the Indian average. Assam also had a lower percentage of deliveries in a health facility, explain the higher infant mortality as well as under-five mortality rate. Arunachal Pradesh have fewer institutional deliveries than Assam, at the same time had a lower infant mortality rate as well as a lower under-five mortality rate.

Geographical location of north eastern states also plays important role in determining both the access delivery and neonatal death. Hilly areas of north east states leads towards a weaker connectivity. Means of transportation like roadways, railways, airways plays vital role in transportation of human being as well as good \& materials.

\section{Methodology}

NFHS 4 data provides data about one-year-old children from the survey date. In the survey, questions were asked for the eligible mother: where their delivery took place, and death of children within 28 days. These questions were asked for the last live birth of the mother. In this current study, we have included the last children born within 12 months before the survey date. Variables have been recoded in the following manner as below for conducting the study:

\subsection{Dependent Variables}

The dependent variables used for the study has been generated, that neonatal death.

\subsection{Independent Variables}

NFHS-4 collected data about a place of delivery to obtain how many infants are delivered in NonInstitution and public institutions and private institutions among survey participants. For this study, variables have been recoded. Because some of the categories having very few frequencies. So for better visualization variables have been recoded.

Categories of a place of delivery were recoded into "Delivery at Non-Institution," "Delivery at Institutions" and generated as a new variable "Institutional Delivery (2)".

Categories of a place of delivery were recoded into "Delivery at Non-Institution," "Delivery at Public Institutions," \& "Delivery at Private Institutions" and generated as a new variable "Institutional Delivery (3)".

The following are used as underlying factors:

- In Maternal factors

Age of mother at birth was recoded as (15-24, 25-34, $35 \&$ above) age group.

Mother's education as (Illiterate, Primary, Secondary, Higher).

- In Socio-Economic Field

Place of residence as (Rural and Urban).

In religion, categories were recoded as (Hindu, Muslim, Christian, Others).

In Caste, categories were recoded as (SC, ST, OBC, Others).

Wealth status was recoded in three broad categories (Poor, Middle, and Rich). 
The following are used as infant factors,

Sex of child as (Male and Female).

Birth order recoded as (1, 2, 3, 4 \& above).

- Model used to Analyze Data

Logistic regression was carried out to percentage distribution of dependent variables within different demographic and socioeconomic characteristics. To understand the determinants of Institutional Delivery status by using STATA software.

Logistic regression analysis was carried out to show dependent variable neonatal death by institutional Delivery. To understand the effect of institutional delivery on neonatal death by using the STATA software.

\section{RESUltS}

In north eastern states of India delivery of children is shared by both non-institution (38.31), an institution (61.69). In Sikkim (94.83) deliveries taken place at institutions, whereas Nagaland is having the highest non-institutional delivery (68.18). Maximum of the states have deliveries in noninstitutional setup, i.e. (less than 50\%). States are Arunachal Pradesh, Assam, Manipur, Meghalaya, Mizoram, Sikkim, and Tripura. That means in those states people are now going for Institutional delivery. Which ultimately reflects reducing in neonatal death in those states.

Among north eastern states of India highest neonatal death prevails in the state of Assam, followed by Tripura, Manipur and other states.

Death of infants within 28 days of their life is highest in Assam (36), but the total live birth of Assam is also high. Whereas Mizoram (12) and Arunachal Pradesh (12) are having few neonatal death and total live birth is also less. This table is showing how the underlying demographic and socio economic factors are affecting the institutional delivery in north eastern states of India.

\subsection{Maternal Factor}

- Age of Mother at Birth: In this category, indicator is associated with institutional delivery. Table 3 presents the percentage of birth took place in an institution is highest among mothers age group (15-24) and lowest among the age group ( $35 \&$ above).

- Mother's Education: In this category also indicator is associated with institutional delivery. Table 3 presents the percentage of birth took place in an institution is highest among mothers (Higher) educational status and lowest among (No education).

Table1: Percentage distribution of Institutional Delivery

\begin{tabular}{|l|l|l|}
\hline \multirow{2}{*}{ North-East India } & Institutional Delivery in (\%) \\
\cline { 2 - 3 } & Non-Institution & Institution \\
\hline Arunachal Pradesh & 49.37 & 50.63 \\
\hline Assam & 29.66 & 70.34 \\
\hline Manipur & 35.49 & 64.51 \\
\hline Meghalaya & 46.83 & 53.17 \\
\hline Mizoram & 24.06 & 75.94 \\
\hline Nagaland & 68.18 & 31.82 \\
\hline Sikkim & 5.17 & 94.83 \\
\hline Tripura & 22.03 & 77.97 \\
\hline Total & 38.31 & 61.69 \\
\hline
\end{tabular}

Table2: Neonatal death in North-Eastern states of India

\begin{tabular}{|l|l|l|l|}
\hline North-East India & Neonatal Death & Total live birth & Neonatal Death per (1000) \\
\hline Arunachal Pradesh & 324 & 26,936 & 12 \\
\hline Assam & 1,873 & 51,952 & 36 \\
\hline Manipur & 425 & 23,573 & 18 \\
\hline Meghalaya & 281 & 18,784 & 15 \\
\hline Mizoram & 273 & 22,379 & 12 \\
\hline Nagaland & 337 & 21,913 & 15 \\
\hline Sikkim & 97 & 6,841 & 14 \\
\hline Tripura & 164 & 7,374 & 22 \\
\hline
\end{tabular}


Table3: Underlying factors on Institutional delivery

\begin{tabular}{|c|c|c|c|}
\hline Underlying Factors & Institutional de & & Total Sample \\
\hline Age of mother at birth & Noninstitution & Institution & \\
\hline $15-24$ & 34.11 & 65.89 & 20543 \\
\hline $25-34$ & 37.73 & 62.27 & 6508 \\
\hline $35 \&$ above & 46.67 & 53.33 & 37142 \\
\hline Mothers Education & & & \\
\hline No education & 65.10 & 34.90 & 7,419 \\
\hline Primary & 51.43 & 48.57 & 6,659 \\
\hline Secondary & 27.82 & 72.18 & 20,633 \\
\hline Higher & 9.63 & 90.37 & 2,431 \\
\hline Birth order & & & \\
\hline 1 & 23.53 & 76.47 & 13,496 \\
\hline 2 & 34.63 & 65.37 & 10,066 \\
\hline 3 & 46.47 & 53.53 & 6,017 \\
\hline $4 \&$ above & 63.10 & 36.90 & 7,563 \\
\hline Sex of child & & & \\
\hline Male & 37.61 & 62.39 & 19,041 \\
\hline Female & 39.05 & 60.95 & 18101 \\
\hline Place of residence & & & \\
\hline Urban & 15.69 & 84.31 & 7,762 \\
\hline Rural & 44.29 & 55.71 & 29,380 \\
\hline Religion & & & \\
\hline Hindu & 18.46 & 81.54 & 10967 \\
\hline Muslim & 47.23 & 52.77 & 5285 \\
\hline Christian & 47.71 & 52.29 & 17823 \\
\hline Others & 39.35 & 60.65 & 3067 \\
\hline Caste & & & \\
\hline $\mathrm{SC}$ & 21.72 & 78.28 & 2150 \\
\hline ST & 45.46 & 54.54 & 22098 \\
\hline $\mathrm{OBC}$ & 18.51 & 81.49 & 3954 \\
\hline Others & 28.99 & 71.01 & 5477 \\
\hline Wealth status & & & \\
\hline Poor & 54.38 & 45.62 & 19932 \\
\hline Middle & 27.72 & 72.28 & 9061 \\
\hline Rich & 10.77 & 89.23 & 8149 \\
\hline
\end{tabular}

Table4: Logistic regression on underlying factors of Institutional Delivery

\begin{tabular}{|c|c|c|c|}
\hline Underlying factor & Odds Ratio & \multicolumn{2}{|c|}{ [95\% Conf. Interval] } \\
\hline \multicolumn{4}{|c|}{ Mother's Age at birth (15-24®) } \\
\hline $25-34$ & $1.16 * * *$ & 1.08 & 1.24 \\
\hline $35 \&$ Above & $1.33 * * *$ & 1.21 & 1.47 \\
\hline \multicolumn{4}{|c|}{ Mothers Education (Illiterate®) } \\
\hline Primary & $1.61 * * *$ & 1.48 & 1.75 \\
\hline Secondary & $2.75 * * *$ & 2.55 & 2.96 \\
\hline Higher & $4.59 * * *$ & 3.88 & 5.44 \\
\hline \multicolumn{4}{|l|}{ Birth Order (1®) } \\
\hline 2 & $0.59 * * *$ & 0.55 & 0.64 \\
\hline 3 & $0.44 * * *$ & 0.41 & 0.48 \\
\hline 4 \& Above & $0.31 * * *$ & 0.28 & 0.34 \\
\hline \multicolumn{4}{|c|}{ Sex Of Child (Male $\AA)$} \\
\hline Female & $0.93 * *$ & 0.88 & 0.98 \\
\hline \multicolumn{4}{|c|}{ Place Of Residence (Rural®) } \\
\hline Urban & $1.86 * * *$ & 1.72 & 2.02 \\
\hline \multicolumn{4}{|l|}{ Religion (Hindu®) } \\
\hline Muslim & $0.30 * * *$ & 0.27 & 0.34 \\
\hline Christian & $0.48 * * *$ & 0.43 & 0.53 \\
\hline Others & $0.57 * * *$ & 0.50 & 0.64 \\
\hline \multicolumn{4}{|l|}{ Caste (SC@) } \\
\hline ST & $0.56 * * *$ & 0.49 & 0.64 \\
\hline
\end{tabular}


Neonatal Death with Relation to Institutional Delivery in North-Eastern States of India

\begin{tabular}{|l|l|l|l|}
\hline \multicolumn{3}{|l|}{} \\
\hline OBC & $1.15^{* *}$ & 0.98 & 1.33 \\
\hline Others & $0.95^{*}$ & 0.82 & 1.10 \\
\hline Wealth Index (Poor () & $2.49 * * *$ & 2.32 & 2.66 \\
\hline Middle & $6.82^{* * *}$ & 6.21 & 7.49 \\
\hline Rich
\end{tabular}

Note: $* * * \mathbf{p}<0.1, * * \mathbf{p}<0.05, * \mathbf{p}<0.01$

Table5: Institutional Delivery and Source Of Assistance: Janani Suraksha Yojana (JSY)

\begin{tabular}{|l|l|l|l|}
\hline \multirow{2}{*}{ North-East India } & Institutional delivery & \multicolumn{2}{|l|}{ Janani Suraksha Yojana } \\
\cline { 3 - 4 } & & No & Yes \\
\hline \multirow{2}{*}{ Arunachal Pradesh } & Public & 77.64 & 22.36 \\
\cline { 2 - 4 } & Private & 96.83 & 3.17 \\
\hline \multirow{2}{*}{ Mansam } & Public & 22.16 & 77.84 \\
\cline { 2 - 4 } & Private & 80.36 & 19.64 \\
\hline \multirow{2}{*}{ Meghalaya } & Public & 64.19 & 35.81 \\
\cline { 2 - 4 } & Private & 89.36 & 10.64 \\
\hline \multirow{2}{*}{ Mizoram } & Public & 67.80 & 32.20 \\
\cline { 2 - 4 } & Private & 91.49 & 8.51 \\
\hline \multirow{2}{*}{ Nagaland } & Public & 48.65 & 51.35 \\
\cline { 2 - 4 } & Private & 73.09 & 26.91 \\
\hline Sikkim & Public & 59.56 & 40.44 \\
\cline { 2 - 4 } & Private & 86.82 & 13.18 \\
\hline \multirow{2}{*}{ Tripura } & Public & 65.55 & 34.45 \\
\cline { 2 - 4 } & Private & 83.15 & 16.85 \\
\cline { 2 - 4 } & Public & 59.01 & 40.99 \\
\hline
\end{tabular}

Table6: Share of Neonatal Death by Institutional Delivery

\begin{tabular}{|l|l|l|l|l|}
\hline \multirow{2}{*}{ North-East India } & \multirow{2}{*}{ Neonatal Death } & \multicolumn{4}{|l|}{ The share of Death by Institutional delivery (\%) } \\
\cline { 3 - 5 } & & Non-Institution & Public & Private \\
\hline Arunachal Pradesh & 324 & 51 & 38 & 10 \\
\hline Assam & 1,873 & 38 & 57 & 5 \\
\hline Manipur & 425 & 43 & 38 & 19 \\
\hline Meghalaya & 281 & 57 & 35 & 8 \\
\hline Mizoram & 273 & 24 & 63 & 13 \\
\hline Nagaland & 337 & 68 & 27 & 5 \\
\hline Sikkim & 97 & 5 & 85 & 10 \\
\hline Tripura & 164 & 17 & 78 & 6 \\
\hline
\end{tabular}

Table7: Logistic regression on Institutional Delivery as an underlying factor of Neonatal Death

\begin{tabular}{|l|l|l|l|}
\hline \multirow{2}{*}{ Underlying Factor } & Neonatal Death \\
\cline { 2 - 4 } & Odds Ratio & \multicolumn{2}{|l|}{ [95\% Conf. Interval] } \\
\hline Institutional Delivery(2) Institution ${ }^{\circledR}$ & $1.18^{* * *}$ & 1.02 & 1.38 \\
\hline Non-Institution & \multicolumn{2}{|l|}{} \\
\hline Institutional Delivery(3) Non-Institution ${ }^{*}$ & $0.87^{* * *}$ & 0.75 & 1.02 \\
\hline Public & $0.67^{* * *}$ & 0.51 & 0.89 \\
\hline Private &
\end{tabular}

Note: Controlled for Demographic and Socio-economic factors. $* * * \mathbf{p}<\mathbf{0 . 1}, * * \mathbf{p}<\mathbf{0 . 0 5}, * \mathbf{p}<\mathbf{0 . 0 1}$

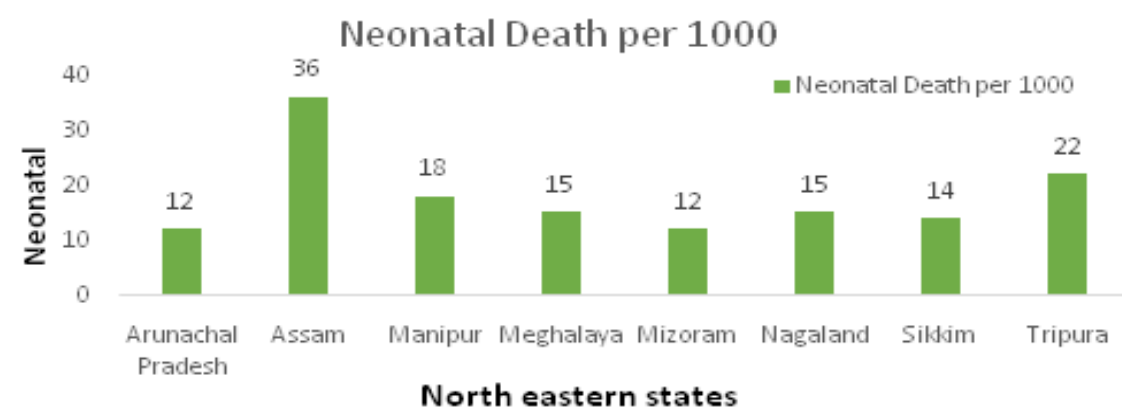

Figure1: Neonatal death in North-Eastern states of India 


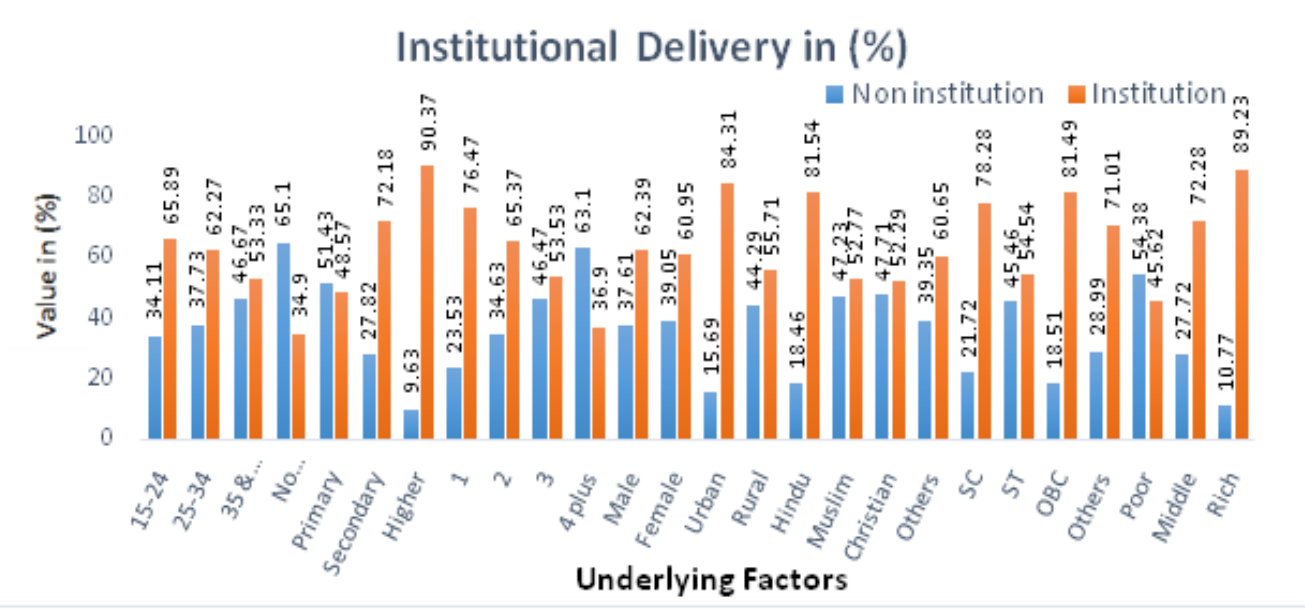

Figure2: Effect of underlying factors on Institutional Delivery

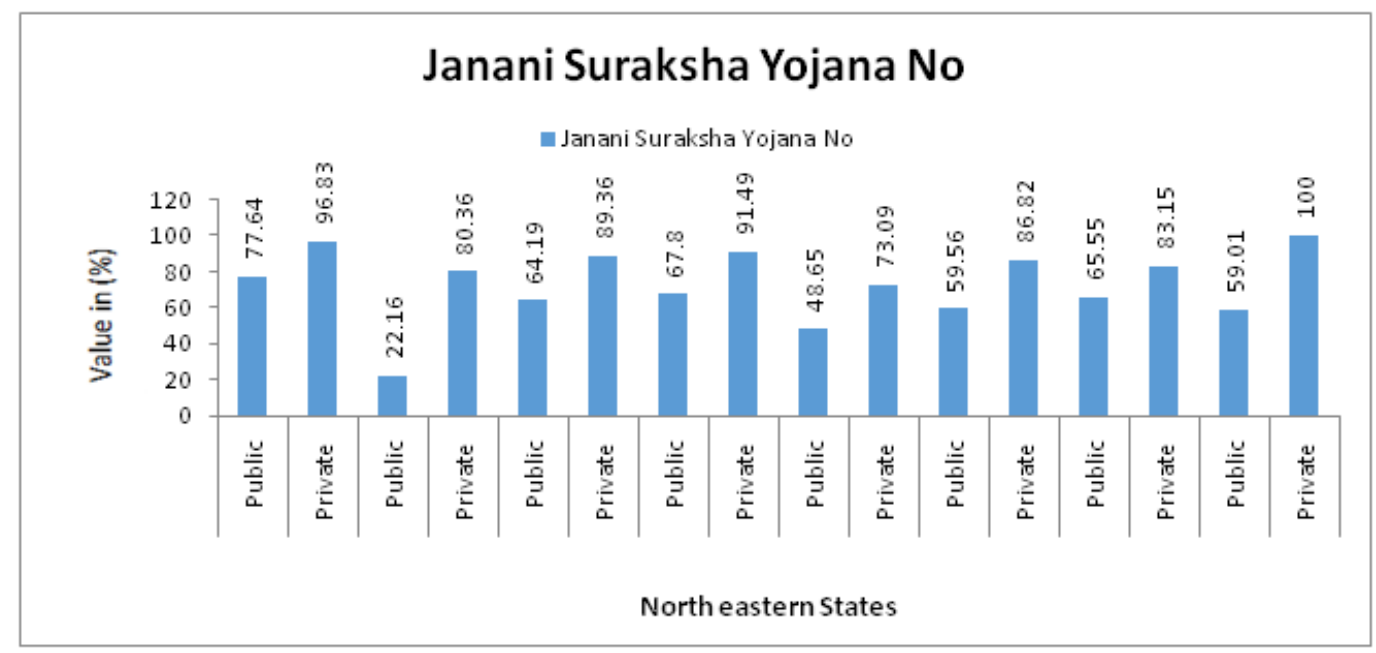

Figure3: Reported as not getting assistance from JSY

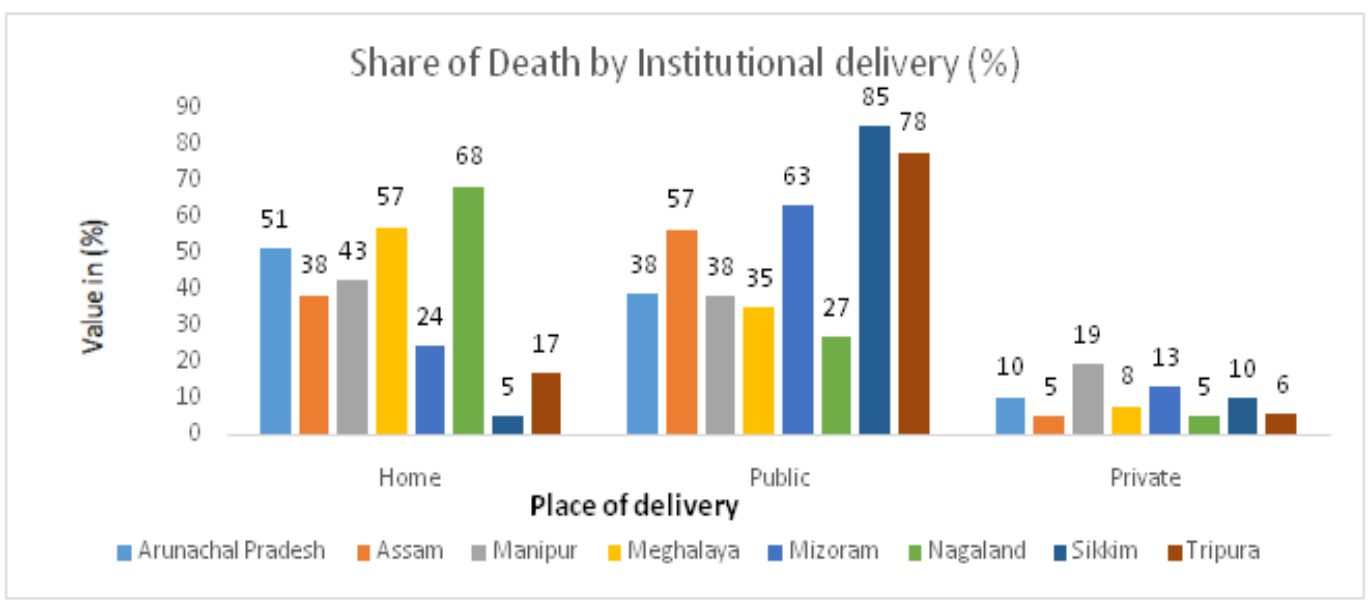

Figure4: Share of Death by Institutional delivery (\%)

\subsection{Infant Factor}

- Birth Order: In this category, it has been found that the order of birth is associated with institutional delivery. Table 3 presents the percentage of birth took place in an institution is highest among birth order (1), followed by (2) and delivery is lowest among (4 and above) birth order.

- Sex of Child: In this category, it has been found that sex of birth is associated with institutional delivery. Table 3 presents the percentage of birth took place in an institution is highest among female followed by the male. 


\subsection{Socio-Economic Factor}

- Place of Residence: In this category, it has been found that the residence of people is associated with institutional delivery. Table 3 presents the percentage of birth took place in an institution is highest among rural followed by urban areas.

- Religion: In this category, it has been found that the religion of people is associated with institutional delivery. Table 3 presents the percentage of birth took place in an institution is highest among Hindu followed by other religious groups.

- Caste: In this category, it has been found that the Caste of people is associated with institutional delivery. Table 3 presents the percentage of birth took place in an institution is highest among SC followed by OBC, others, and ST peoples.

- Wealth Index: In this category, it has been found that the wealth status of the family is associated with institutional delivery. Table 3 presents the percentage of birth took place in an institution is highest among rich followed by middle and poor peoples.

By running logistic regression on institutional delivery $\&$ associated factors in north eastern states, it is found that:

\section{Maternal Factor}

- Age of mother at birth: In this category by keeping age group (15-24) as base it is found that- Age group (25-34) is 1.16 indicates that the event is more likely to occur in the first group, and it is statistically significant to base, delivery at institutions by age group (15-24), and age group ( 35 \& above) is 1.33 indicates that the event is more likely to occur in the first group, and it is statistically significant to base, delivery at institutions by age group (15-24).

- Mother's education: In this category by keeping Illiterate as base it is found that- Primary is (1.61) indicates that the event is more likely to occur in the first group, and it is statistically significant to base, Secondary is (2.75) suggests that the fact is more likely to happen in the first group, and it is statistically significant to base delivery at institutions by illiterates.

\section{Infant Factor}

- Birth order: In this category by keeping first birth order as base it is found that- second birth order is (0.59) indicates that the event is less likely to occur in the first group, and it is statistically significant to base, third birth order is $(0.44)$ and birth order $4 \&$ above is $(0.31)$ indicates that the events are less likely to occur in the first group, and it is statistically significant to base delivery at institutions by first birth order.

- Sex of child: In this category, by keeping the male child as a base it is found that the female child is (0.93) indicates that the event is less likely to occur in the first group, and it is statistically significant to base delivery at institutions by a male child.

\section{Socio-Economic Factor}

- Place of residence: In this category, by keeping rural residence as a base it is found that- urban residence is (1.86) indicates that the event is more likely to occur in the first group, and it is statistically significant to base delivery at institutions by rural residence.

- Religion: In this category by keeping Hindu as base it is found that- Muslim is (0.30) indicates that the event is less likely to occur in the first group, and it is statistically significant to base, Christian is (0.48) and other religion is (0.57) indicates that the events are less likely to occur in the first group, and it is statistically significant to base delivery at institutions by Hindu.

- Caste: In this category by keeping SC as base it is found that- ST is (0.56) indicates that the event is less likely to occur in the first group, and it is statistically significant to base, OBC is (1.15) indicates that the event is more likely and other caste is (0.95) indicates that the event is less likely to occur in the first group, and these are not statistically significant to base delivery at institutions by SC.

- Wealth Index: In this category by keeping Poor as base it is found that- Middle is (2.49) indicates that the event is more likely to occur in the first group, and it is statistically significant to base, 
Rich is (6.82) indicates that the events are more likely to occur in the first group, and it is statistically significant to base delivery at institutions by Poor.

- Janani Suraksha Yojana: The JSY scheme aims to encourage poor pregnant women to give birth in registered health institutions where medical staffs are on-hand if something goes wrong talking about the influence of Source of Assistance: Janani Suraksha Yojana (JSY). Maximum states reported that they are not getting assistance whether delivery took place in public or private. In Sikkim delivery in private institution (100\%) said that they are not getting any help from JSY. Usually, the programmes and policies play a significant role to have a delivery either at a public institution or private institution.

\subsection{Logistic Regression on Neonatal Death by Institutional Delivery}

By running regression on the dependent variable neonatal death by considering institutional delivery as independent variable it is found that:

- Institutional Delivery (2): Here institutional delivery was categorized into two types, delivery at Non-Institution and delivery at an institution. By keeping delivery at an institution as a base, it is found that- Non-Institution is (1.18) indicates that the event is more likely to occur, and it is statistically significant to base delivery at an institution.

- Institutional Delivery (3): Here institutional delivery was categorized into three types, delivery at Non-Institution and delivery at a public institution and private institution. This time by keeping delivery at Non-Institution as a base it is found that- the public institution is $(0.87)$ and the private institution is (0.67) indicates that the events are less likely to occur, and these statistically significant to base delivery at Non-Institution.

\section{DISCUSSION}

Variations in place of delivery playing important role in survival of a new born baby. Delivery taking place in institutions tends to have less number of new born death in comparison to those delivery occurring at home. Because the care for new born plays an important role here. As from reviewing the literature it is found that health institutions provide equipment's which keeps the baby safe after a delivery. Within the institution private institutions provide better result. As some of the literature suggest that public institutions are lacking with facilities and providers. In some cases one doctor regulates all the health problem in public institutions. Whereas private institutions are having specialised doctors. Interestingly with contrast to general pattern in Manipur it is found that Private institutions contributing to more neonatal death. As from newspaper the bitter reality suggest that in private institutions health care providers have a profit motive, sometimes practitioners were not well trained.

North eastern region of India having low neonatal death with compare to other regions of India. Except one state i.e. Assam is having neonatal death above 30. As cited in different literatures a particular conclusion was made. That is in Assam the Tea garden worker are contributing to more neonatal death. Because most of the time they were busy in their work. So care for a newborn was lacking.

While it is found that the statistical values are also supporting findings at a good confidence level. Demographic, socioeconomic factors are really playing very important role in deciding whether the delivery of a baby would take place in home or institutions. If institutions then in public or private institutions. Assistance from Janani Suraksha Yojana (JSY) had a main role in determining the delivery place.

Institutions delivery is playing an important role in saving the life of new born baby. Because in care to home delivery institutional delivery is showing less likelihood of occurrence of the event called neonatal death.

Again it can be said that both private and public institution delivery are contributing to neonatal survival. So excluding other factors of neonatal death, institutional delivery is one of the major factor and it is reflected from the results. In future research can be done on influence of other factor in determining the neonatal death statistics of north eastern states of India. 
Geographically isolation of north eastern states from the main land of India, hilly terrain, connectivity network (Road, Rail, and Air) these all are factors which contributing to backwardness of north eastern states. But despite having these natural barriers this region has come out as a role model for other regions of India. Governments of EAG states can take lesson from northeast Indian states, in determining their states policies regarding healthcare facilities to their people.

\section{CONCLUSION}

However, this study indicates the role of different socio-economic factors on institutional delivery as a part of to promote neonatal survival. The above analysis demonstrates the data of neonatal death among eight states of North-East India. Where it was found that institutional delivery is associated with neonatal death. But the influence of institutional delivery is not much on neonatal death. This may be because there are several variables which affect the pattern of neonatal death of an area. North eastern states are geographically marginalized from the mainland of India, so any programmes taken at government level does not reach in north eastern states of India. As from the study it is found that neonatal mortality is still higher in Assam, because as from some of the literature I found that in Assam Tea garden population are more risk of neonatal death. Except the main factor institutional delivery other factors also plays important role in neonatal death. Geographical concepts can able to explain the reasons to uneven distribution of neonatal death with relation to neonatal death.

\section{REFERENCES}

[1] Mohanty SK, et al. (2019) "Out-of-pocket expenditure and correlates of caesarean births in public and private health centres in India." Social science and medicine 224 (2019) 45-47

[2] Singh A. et.al. (2014) "Do antenatal care interventions improve neonatal survival in India?" Health Policy and Planning 2014; 29:842-848 doi:10.1093/heapol/czt066

[3] The million death study collaborators "Causes of neonatal and child mortality in India: a nationally representative mortality survey." Lancet Volume 376, Issue 9755, p.1853-1860

[4] Chowdhury M, et al. (2005) "Neonatal Mortality in Rural Bangladesh: An Exploratory Study." Journal of Health, Population, and Nutrition, Vol. 23, No. 1 (March 2005), pp. 16-24

[5] Shah and Dwivedi (2011) "Causes of Neonatal Deaths among Tribal Women in Gujarat, India." Population Research and Policy Review, Vol. 30, No. 4 (August 2011), pp. 517-536

[6] Merlo J, et al. (2005) "Hospital Level of Care and Neonatal Mortality in Low- and High-Risk Deliveries: Reassessing the Question in Sweden by multilevel analysis.” Medical Care, Vol. 43, No. 11 (Nov., 2005), pp. 1092-1100

[7] Demise A, et al. (2015) "Prospective Audit of Avoidable Factors in Institutional Stillbirths and Early Neonatal Deaths at Tikur Anbessa Hospital in Addis Ababa, Ethiopia."

[8] African Journal of Reproductive Health / La Revue Africaine de la Santé Reproductive, Vol. 19, No. 4 (December 2015), pp. 78-86

[9] Adjuik M, et al. (2006) "Cause-Specific Mortality Rates in Sub-Saharan Africa and Bangladesh." Bull World Health Organ. Vol84 (3):181-88.

[10] Misselhorn M, Harttgen K. (2006) "A multilevel approach to explain child mortality and under nutrition in South Asia and sub-Saharan Africa." Research Committee Development Economics. 2006. No. 20.

[11] Susuman A.S. (2012) "Child mortality rate in Ethiopia." Iran J Public Health. Vol41 (3):9-19.

[12] Ayele DG, Zewotir TT. (2016) "Childhood mortality spatial distribution in Ethiopia." J Appl Stat. 2016; vol43 (15):2813-28.

[13] Altman R et al. (2017) "Is Institutional Delivery Protective against Neonatal Mortality among Poor or Tribal Women? A Cohort Study from Gujarat, India”. Maternal \& Child Health J (2017) 21:1065-1072 DOI 10.1007/s1095-016-222-y

[14] Fink G et al. (2015) "Institutional deliveries weakly associated with improved neonatal survival in developing countries: evidence from 192 Demographic and Health Surveys". International Journal of Epidemiology, 2015, 1879-1888 doi: 10.1093/ije/dyv115

[15] Goudar et al. (2015) "Institutional deliveries and perinatal and neonatal mortality in Southern and Central India." Reproductive Health 2015, 12(Supple 2): S13

[16] Shahabuddin A et al. (2011) "Determinants of institutional delivery among young married women in Nepal: Evidence from the Nepal Demographic and Health Survey, 2011". Evidence from the Nepal Demographic and Health Survey, 2011. BMJ Open 2017; 7:e012446. DOI: 10.1136/ bmjopen-2016012446 
[17] Ajaari J et al. (2012) "Impact of Place of Delivery on Neonatal Mortality in Rural Tanzania". International Journal of MCH and AIDS (2012), Volume 1, Issue 1, Pages 49-59

[18] Goudar S et al. (2015) "Institutional deliveries and perinatal and neonatal mortality in Southern and Central India”. Reproductive Health 2015, 12(Supple 2):S13

[19] Fink G et al. (2015) "Institutional deliveries weakly associated with improved neonatal survival in developing countries: evidence from 192 Demographic and Health Survey".

[20] International Journal of Epidemiology, 2015, 1879-1888 doi: 10.1093/ije/dyv115 Advance Access Publication Date: 30 June 2015 Original article.

[21] Kidanu et al. (2017) "Factors influencing institutional delivery service utilization in Dembecha district, Northwest Ethiopia: A community based cross sectional study". Reproductive Health (2017) 14:98 DOI 10.1186/s12978-017-0359-5

[22] Pathak P et al. (2015) "Factors Associated with the Utilization of Institutional Delivery Service among Mothers". Nepal Health Research Council 2017 Sep- Dec; 15(37):228-34

\section{AUTHORS' BIOGRAPHY}

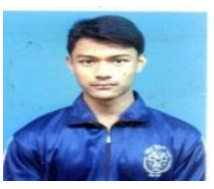

Tushar Dakua has completed M.Phil from IIPS, Mumbai, India. He has done his M.A in Geography fro VIDYASAGAR UNIVERSITY, Midnapore

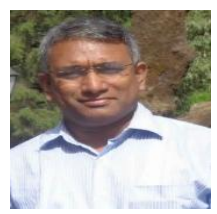

Dr. Manoj Alagarajan, Assistant Professor, M.A., M.Phil., Ph.D., (Bharathiar University), Mumbai

Citation: Tushar Dakua. "Neonatal Death with Relation to Institutional Delivery in North-Eastern States of India”. International Journal of Research in Geography. vol 5, no. 2, 2019, pp.19-28. doi: http://dx.doi.org/10. 20431/2454-8685.0502003.

Copyright: (C) 2019 Authors. This is an open-access article distributed under the terms of the Creative Commons Attribution License, which permits unrestricted use, distribution, and reproduction in any medium, provided the original author and source are credited. 